\title{
International Service Learning Project on Environmental Improvement and Sustainable Development for Nepal Earthquake Relief
}

\author{
Daniel C. W. Tsang, Lu B. L. Khoo, Iris K. M. Yu, and Nicole S. N. Yiu
}

\begin{abstract}
This international service learning project aimed to enhance post-disaster living environment and sustainable community development while enhancing student's learning experience and developing desirable graduate attributes. A total of 40 undergraduate and postgraduate students from multiple disciplines participated in this project. Pre-trip preparation workshops were organized according to four key themes, namely 1) water supply, 2) wastewater treatment, 3) health and safety education, and 4) GPS mapping. During the stay in Nepal, the students conducted GPS surveying, water supply mapping, health and hygiene teaching, toilet and house rebuilding projects, family visits, engagement activities, as well as cultural exchange workshops. Both qualitative and quantitative assessments were given to students at different programme stages, including reflective journals, questionnaires, and group interviews. Students' learning outcomes are holistically evaluated under scope of academic learning, service experience, and personal development. The results suggest that realisation of global citizenship, understanding local context and problems, application of engineering knowledge in real-life situation, and interpersonal communication skills in a culturally diversified environment were the most significant learning outcomes. We compared the feedback of this voluntary programme with those of mandatory programmes, and highlighted the similarities and discrepancies for the purpose of enhancing students' experiential learning in future programmes.
\end{abstract}

Index Terms-Environmental iimprovement, international service learning, experiential learning, sustainable development, global citizenship, self-directed learner.

\section{INTRODUCTION}

Post-disaster relief and community resilience is one of the major challenging issues in the 21st century. Although natural disasters have impacted the affected population economically and socio-psychologically as well as the living environment in substantial ways, most governments and NGOs focus on emergency relief and with very limited resources left available for the long-term relief programme. Natural disasters also generate another crisis which the poor living standard of victims has got even worse, and most of them suffer anxiety from uncertainties and vicious poverty.

On 25 April 2015, the 7.8-magnitude earthquake heavily hit Nepal, one of the poorest countries in the world which over

Manuscript received January 17, 2018; revised June 23, 2018. This work was supported by the Hong Kong Polytechnic University Community Service Fund.

The authors are with the Department of Civil and Environmental Engineering, The Hong Kong Polytechnic University, Hung Hom, Kowloon, Hong Kong, China (corresponding author: Daniel C. W. Tsang; e-mail: dan.tsang@polyu.edu.hk).
$30 \%$ of country population still live below the national poverty line. The earthquake not only killed over 9,000 Nepalese people but also hundreds of thousands were made homeless after the entire villages crumbled. It was reported that the residential buildings were strongly damaged or completely lost while existing dam, unreinforced masonry and reinforced concrete structures were heavily deconstructed [1], [2]. The earthquake has also resulted in disastrous damage to natural environment and geotechnical conditions including landslides, rock fall, water pollution, soil contamination, and the increasing risk for deforestation [3]. All of the above are posing a severe threat to the sustainability of both environment and local livelihood in the long run. Deeper understandings with strong commitment to long-term relief work are thus necessary to tackle all these post-disaster related problems and challenges.

This overseas service learning project was organized by the Department of Civil and Environmental Engineering (CEE) of the Hong Kong Polytechnic University (PolyU) and supported by the local non-governmental organization partner, Future Village Nepal (FV, a grass-rooted registered charity organization in Katunge Village which is $100 \mathrm{~km}$ northwest far from Kathmandu, Nepal). This project aimed to address the above post-disaster challenges by contributing our professional knowledge to help the earthquake victims to enhance the overall living environment and sustainable community development. The project also enhanced PolyU students' awareness to the post-disaster issues and encouraged them to develop into global citizens by participating into the long-term relief programme. This can be achieved by adopting the Kolb's experiential learning theory [4], [5] and Onion Model [6], [7] to facilitate students' learning experiences and self-development (Fig. 1). Students were expected to transform their service experiences to knowledge and assist their personal development through service experience and reflection processes.

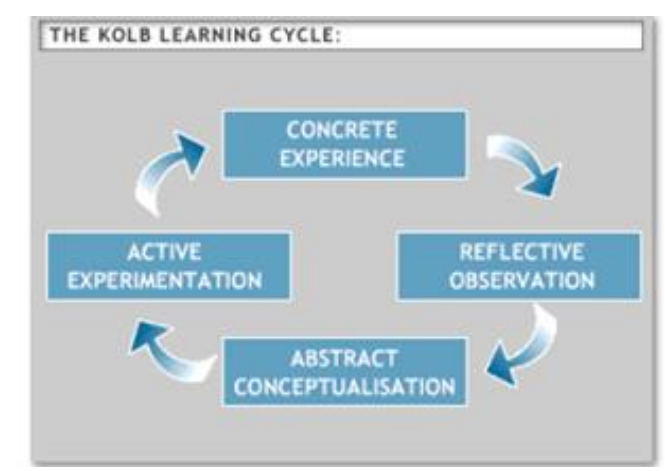

Fig. 1. Kolb’s experiential learning cycle [4]. 


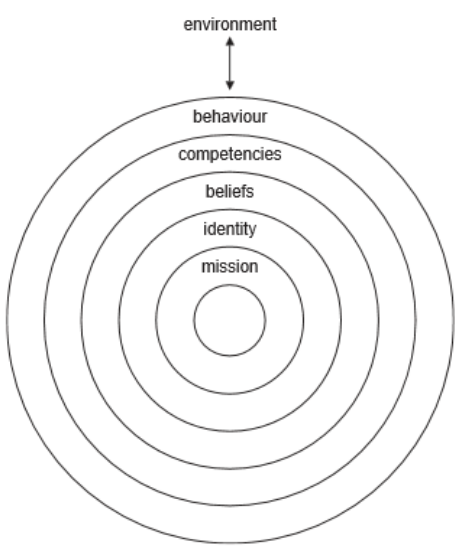

Fig. 2. Onion model [6]. [7].

Under experiential learning cycle and onion model, as shown in Fig. $1 \& 2$, a range of teaching activities were designed to assist the participated students to have deeper reflection on possibilities of problems solving and self-beliefs and personal development [8], [9]. By partnering with FV, students were given real-life cases on environmental problems and hands-on experience to practice their knowledge.

Although service learning projects in a disaster zone are occasionally organized by educational institutions, holistic evaluation of the project deliverables at multiple stages in a qualitative and quantitative manner is seldom reported in the literature. The findings of this study serve as an important reference for future programme designs to enhance students' learning experience.

\section{Service Programme}

\section{A. Service Target - Katunge Village}

The project targeted to assist 130 families (about 750 villagers) from Katunge Village, Dhading, to enable the villagers to enjoy a better living environment and, recover from earthquake impacts. It is located about 6-hour drive from Kathmandu and it is one of the most affected regions in Nepal earthquake. Most of the villagers are farmers with annual income of about 8-month food harvested, and they have to work as porter or construction worker in non-farming season to get enough food for their families. After the earthquake in April 2015, most of the village houses and schools are destroyed. Villagers are now staying in temporary shelter made of zinc metal sheets and canvas.

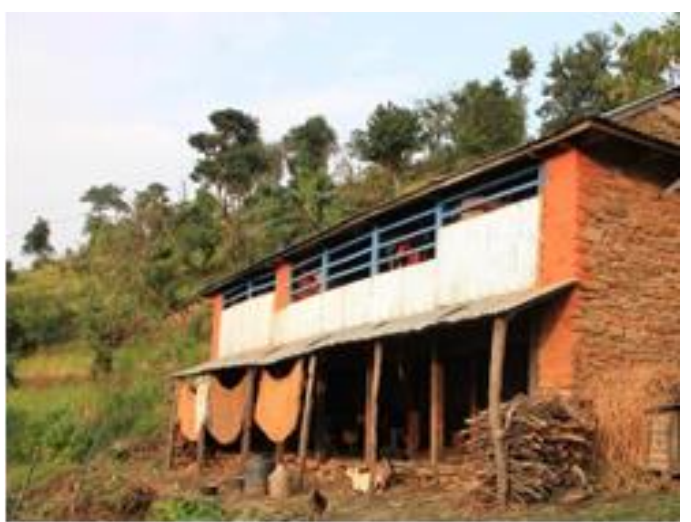

Fig. 3. Local village house before the earthquake.

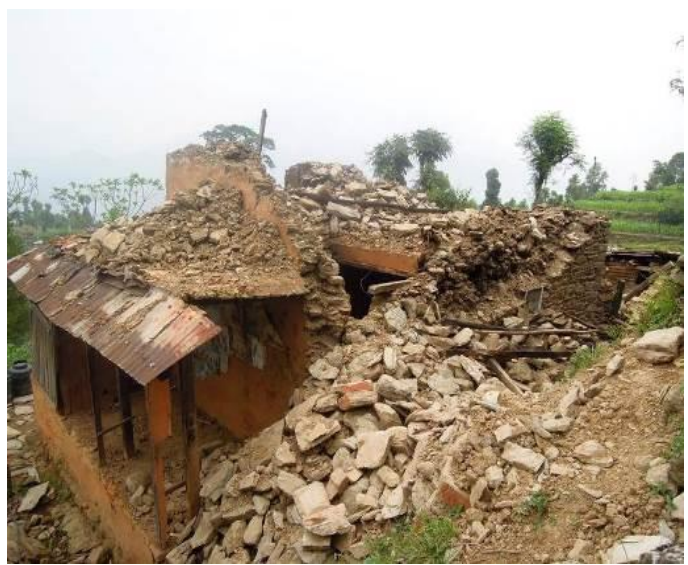

Fig. 4. Local village house after the earthquake.

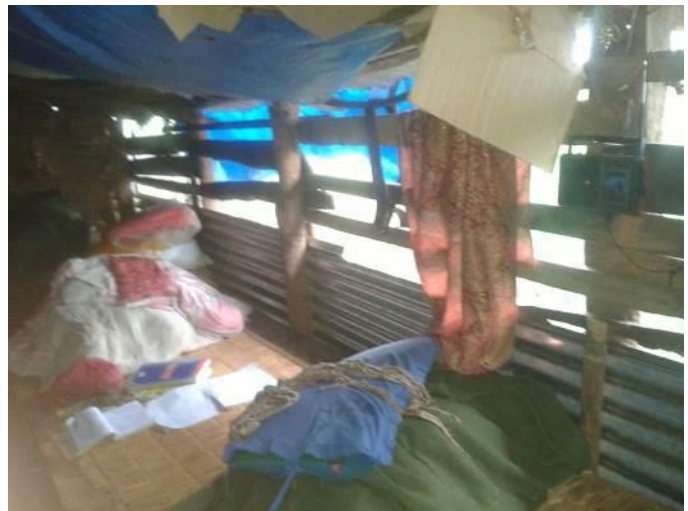

Fig. 5. Temporary shelter lived by the villagers.

Based on FV's field visits in 2015 (from August, December 2015 and January 2016), villagers lost confidence in life and were deeply worried about the future, particularly on the need for a safe shelter and a home to live on. Our PolyU CEE team worked together with FV to help local villagers overcome this challenge and enhance post-disaster community redevelopment. With PolyU CEE's research strength on environmental protection and health/safety, together with the input of local experts from $\mathrm{FV}$, our students were guided to develop environmental improvement schemes to enhance the living environment and human health of the villagers. In addition to post-disaster relief, we took this project opportunity to enhance community development and sustainable development.

\section{B. Project Implementation}

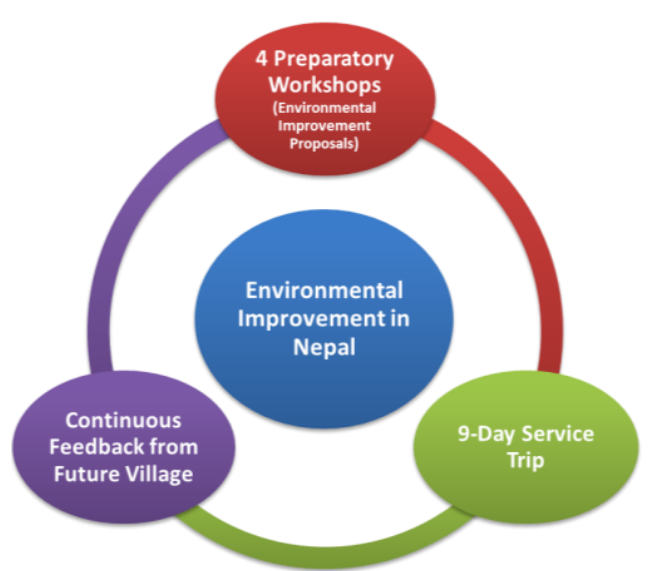

Fig. 6. Core elements of the project.

Out of more than 110 students registered for information 
and interview session, 40 undergraduate/postgraduate students who showed keen interest in learning, collaboration and service were selected to join the programme. The details of the activities conducted are shown in Table I.

In summary, before the 9-day trip to Nepal, four preparatory workshop sessions were conducted by PolyU CEE staff and FV volunteers to equip students with better understanding of local culture in Nepal, identify environmental problems, present proposals to $\mathrm{FV}$ representatives and revise their plans according to recommendations.

TABLE I: LIST OF ACTIVITIES IN THE SERVICE LEARNING PROJECT

\begin{tabular}{|l|l|}
\hline Events (Date) & Activities \\
\hline $\begin{array}{l}\text { Information and } \\
\text { (5 October 2016) }\end{array}$ & $\begin{array}{l}\text { - Introduced the project and selection of } \\
\text { participants. } \\
\text { - Conducted small group interviews with } \\
\text { selection criteria based on four potential } \\
\text { benefits of Service Learning to students } \\
\text { (Academic and intellectual outcomes; } \\
\text { civic outcomes; social outcomes; } \\
\text { personal outcome) }\end{array}$ \\
\hline $\begin{array}{l}\text { Preparatory Workshop 1 } \\
\text { (12 October 2016) }\end{array}$ & $\begin{array}{l}\text { - Explained cultural background in Nepal } \\
\text { and current situation in Future Village } \\
\text { Nepalese Culture Discovery. } \\
\text { - Conducted baseline survey on students' } \\
\text { competences. }\end{array}$ \\
\hline $\begin{array}{l}\text { Preparatory Workshop 2 } \\
\text { (26 October 2016) }\end{array}$ & $\begin{array}{l}\text { Introduced basic knowledge on } \\
\text { assessment of environmental safety and } \\
\text { health as well as disaster management. }\end{array}$ \\
\hline $\begin{array}{l}\text { Preparatory Workshop 3 } \\
\text { (9 November 2016) }\end{array}$ & $\begin{array}{l}\text { - Introduced the methodology of water } \\
\text { supply and wastewater treatment. }\end{array}$ \\
\hline $\begin{array}{l}\text { Preparatory Workshop 4 } \\
\text { (30 November 2016) }\end{array}$ & $\begin{array}{l}\text { - Project Team presented their project } \\
\text { plans, followed by comments given by FV } \\
\text { volunteers and CEE staff. } \\
\text { - Followed up with FV on modifications } \\
\text { of toilet designs and teaching plans. }\end{array}$ \\
\hline & $\begin{array}{l}\text { - Stayed in Future Village: Surveying, } \\
\text { teaching, rebuilding projects and cultural } \\
\text { explorations. } \\
\text { - Visited historical monuments and } \\
\text { Kumbeshwar Technical School. } \\
\text { - Invited speakers from Nepal } \\
\text { Engineering College and local NGOs. } \\
\text { - Conducted mid- and post-trip reflective }\end{array}$ \\
& $\begin{array}{l}\text { journals and survey of students' } \\
\text { achievements. }\end{array}$ \\
\hline
\end{tabular}

Throughout these processes, students were given opportunity to: (i) discuss and identify problems that disaster-impacted communities are facing in association with environmental issues and living environment; and (ii) develop a feasible solution to address the problem identified and evaluate and revise the proposed solution jointly with the villagers and local NGO (FV).

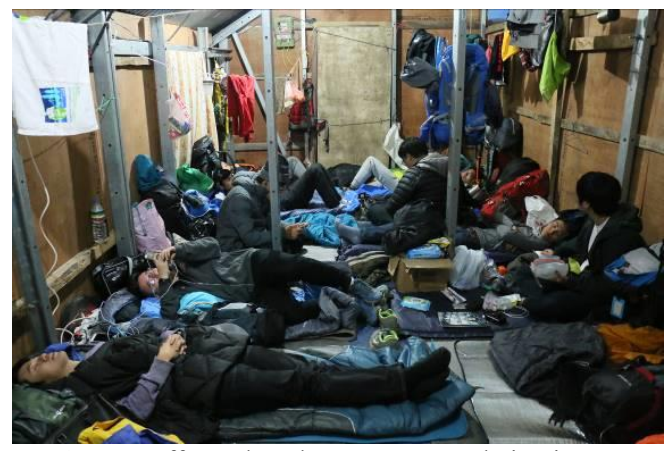

Fig. 7. Staff's and students' accommodation in FV.
During the 9-day trip to Nepal, the students stayed in FV to exercise surveying, teaching, rebuilding projects and cultural explorations, explored the local cultures by visiting the historical sites and communicating with various invited local/foreign speakers. Key activities and milestones accomplished are illustrated in Fig. 7-14.

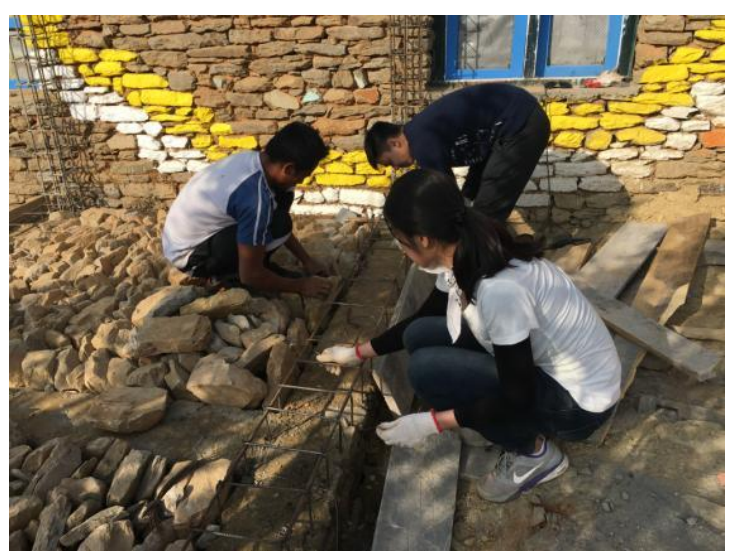

Fig. 8. Toilet design and (partial) construction by student groups.

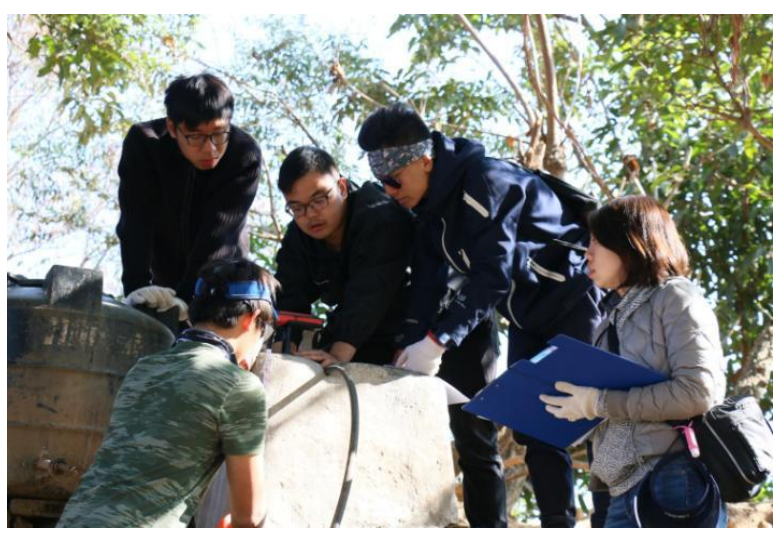

Fig. 9. Water supply system survey by student groups.

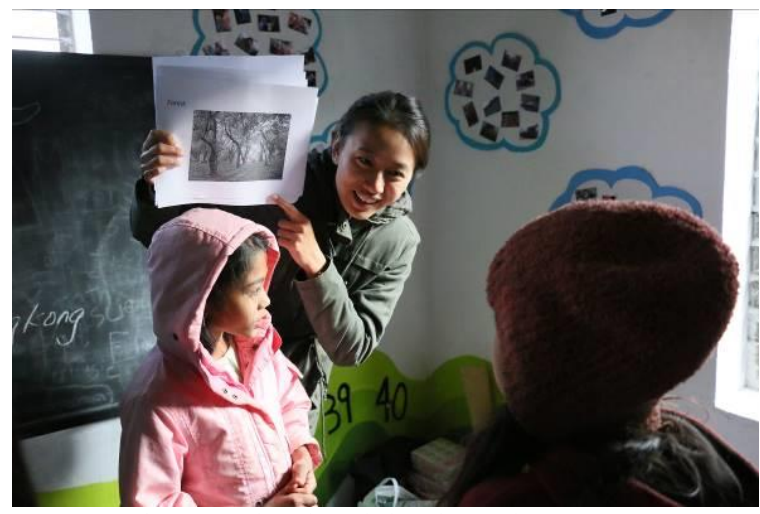

Fig. 10. Cultural workshop by student groups.

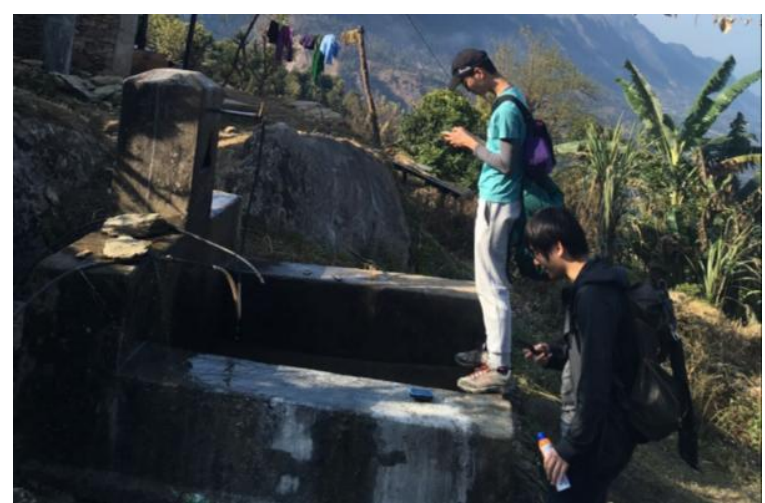

Fig. 11. GPS mapping by student groups. 


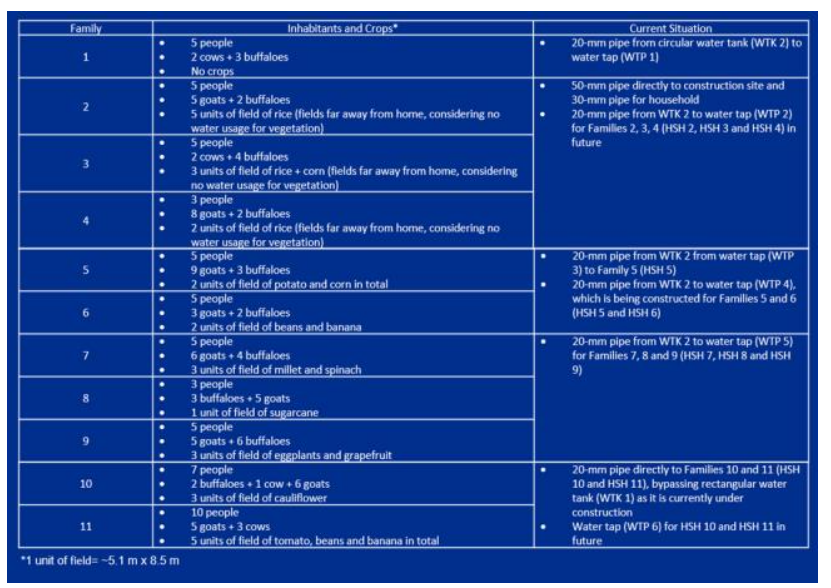

Fig. 12. Results of household water need survey by student groups.

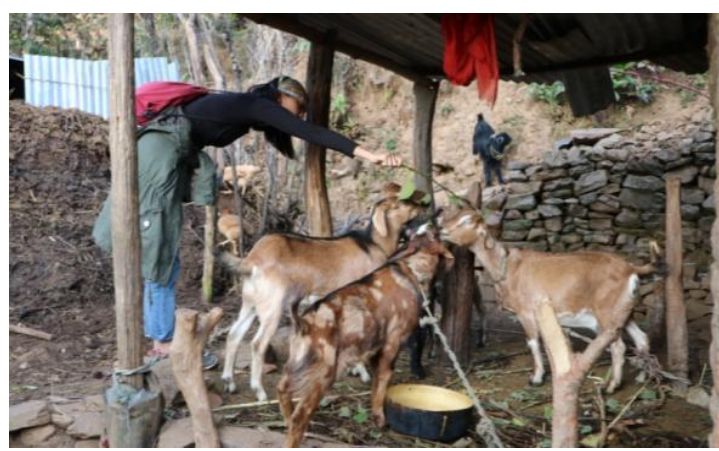

Fig. 13. Family visit and household water need survey by student groups.

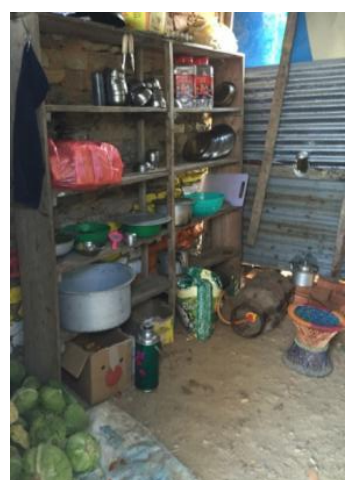

Fig. 14. Family visit and household water need survey by student groups.

\section{INTENDED LEARNING OUTCOMES}

With respect to the revised Bloom's taxonomy (cognitive domain) for teaching and learning, this project proposed seven knowledge-based intended learning outcomes (ILOs). Participated students could:

ILO1. Identify and describe problems in real-life settings of local communities [level of comprehending];

ILO2. Analyse the long-term need of disaster-impacted communities and develop their role as a global citizen in society [level of analysing];

ILO3. Apply the necessary knowledge for environmental improvement and human health through preparatory workshops [level of applying];

ILO4. Develop and evaluate generic competence of innovative problem solving, communication and teamwork [level of creating and evaluating];

ILO5. Design and compare possible solutions to solve the identified problems before the service trip [level of creating and evaluating];
ILO6. Appraise and reflect on their proposals jointly with the villagers and local NGO during and after the service trip [level of evaluating].

\section{Evaluation METHODS}

The outcomes and achievements of the project were evaluated on the basis of students' opinions towards different issues, which were collected by the following means.

- Pre-trip questionnaire survey (for ILOs 3 and 4) and reflective journal (for ILOs 2, 3, 4 and 5)

- Mid-trip reflective journal (for ILOs 2, 3, 4, 5 and 6)

- Post-trip questionnaire survey (for ILOs 3 and 4), reflective journal for (ILOs 1, 2, 3, 4 and 5) and interview (for ILOs 2, 3, 4 and 5)

In particular, the questionnaire adopted the standard survey questions suggested by the Office of Service Learning of the Hong Kong Polytechnic University. The final version consisted of 36 questions which incorporated the concepts of the Experiential Learning Cycle [4], [5], [8], Onion Model [6], [7]. [9] and "Mandatory service-learning: Do students learn from it?", for comparison with mandatory service learning courses. The experiential learning processes and achievable layers of onion model are stated in Table II.

TABLE II: DESIGN OF PRE- AND POST-TRIP QUESTIONNAIRE SURVEY

\begin{tabular}{|c|c|c|}
\hline Questions & $\begin{array}{l}\text { Attributes for Service } \\
\text { Learning }\end{array}$ & $\begin{array}{l}\text { Experiential Learning } \\
\text { Process }\end{array}$ \\
\hline $1-4$ & $\begin{array}{l}\text { Better understanding of } \\
\text { own strengths \& } \\
\text { weaknesses }\end{array}$ & $\begin{array}{l}\text { Concrete experience } \\
\text { and active } \\
\text { experimentation }\end{array}$ \\
\hline $5-8$ & $\begin{array}{l}\text { Communicating } \\
\text { effectively with peers, } \\
\text { collaborators \& service } \\
\text { user }\end{array}$ & $\begin{array}{l}\text { Concrete experience and } \\
\text { reflective observation }\end{array}$ \\
\hline $9-12$ & $\begin{array}{l}\text { Solving challenging } \\
\text { real-life problems }\end{array}$ & $\begin{array}{l}\text { Reflective observation, } \\
\text { abstract } \\
\text { conceptualisation and } \\
\text { active experimentation }\end{array}$ \\
\hline 13 & $\begin{array}{l}\text { Better understanding of } \\
\text { the problems of the } \\
\text { underprivileged }\end{array}$ & $\begin{array}{l}\text { Reflective observation } \\
\text { and active } \\
\text { experimentation }\end{array}$ \\
\hline $14-16$ & $\begin{array}{l}\text { Increased } \\
\text { interest/commitment to } \\
\text { serve people in need }\end{array}$ & $\begin{array}{l}\text { Concrete experience, } \\
\text { reflective observation } \\
\text { and active } \\
\text { experimentation }\end{array}$ \\
\hline $17-20$ & $\begin{array}{l}\text { Working effectively in } \\
\text { teams }\end{array}$ & $\begin{array}{l}\text { Concrete experience, } \\
\text { reflective observation, } \\
\text { and active } \\
\text { experimentation }\end{array}$ \\
\hline $21-25$ & Thinking critically & $\begin{array}{l}\text { Concrete experience, } \\
\text { reflective observation, } \\
\text { abstract } \\
\text { conceptualisation and } \\
\text { active experimentation }\end{array}$ \\
\hline $26-28$ & $\begin{array}{l}\text { Applying knowledge to } \\
\text { deal with complex issues }\end{array}$ & $\begin{array}{l}\text { Concrete experience, } \\
\text { abstract } \\
\text { conceptualisation and } \\
\text { active experimentation }\end{array}$ \\
\hline $29-32$ & $\begin{array}{l}\text { Becoming a more } \\
\text { responsible community } \\
\text { member/ global citizen }\end{array}$ & $\begin{array}{l}\text { Reflective observation } \\
\text { and active } \\
\text { experimentation }\end{array}$ \\
\hline $33-36$ & $\begin{array}{l}\text { Cross-cultural awareness } \\
\& \text { skills }\end{array}$ & $\begin{array}{l}\text { Concrete experience, } \\
\text { Reflective observation } \\
\text { and active } \\
\text { experimentation }\end{array}$ \\
\hline
\end{tabular}




\section{RESULTS AND DISCUSSION}

\section{A. Students'Learning}

In summary, as reflected by the questionnaire results (Fig. 15), the intellectual, social, civic, and personal development of students improved as the mean scores of questions in different categories generally increased after the trip. In addition, students participated in this voluntary service learning project gave higher mean scores in all the categories (6.98 to 8.13), compared to the mandatory service learning subject in PolyU (5.63). In particular, the students showed an increase of confidence in communication skills (Q5-8, $+7.64 \%)$ and problem solving $(\mathrm{Q} 9,+8.9 \%)$.

The distinctive condition in Nepal served as an impressive learning environment where relevant engineering/surveying knowledge, interpersonal and life-skills could be obtained under both active and passive learning process. Upon service experience, critical evaluation and self-reflection, students analysed the actual needs in Nepal, identified challenges, and proposed possible solutions for environmental improvement.
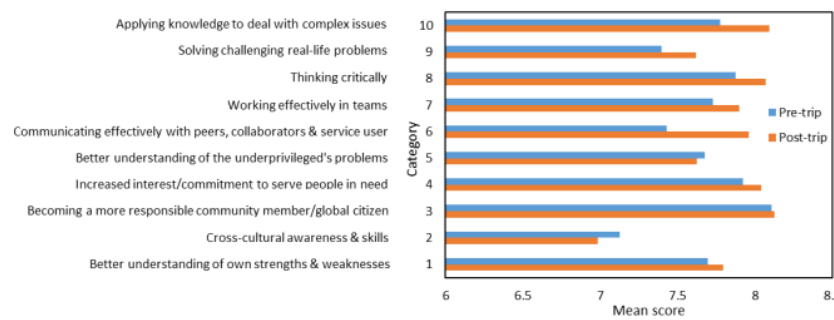

Fig. 15. Results of pre- and post-trip questionnaire survey conducted during this Nepal service learning trip.

Hands-on experience brought students to enrich the information, arguments, and different viewpoints, and reached a sound judgement on the basis of knowledge and discussion on cultural and religious issues. During the course of the project, students were put in a position to think critically about their self-experience and sharing from mentors. The valuable discussion examined and critiqued the validity of credible evidence and logical reasoning, and took a step further to realize the difference in the real world.

As reflected by mid-trip and post-trip reflective journals, students developed multiple skills in academic learning, service experience, and personal development under such a complex and uncertain situation. When considering the circumstances in Nepal under the concern of environment and sustainability, attributes which highlighted knowledge, skills and attitudes were required. To cope with emergencies in new environment, problem-solving skills (e.g., problem analysis, solution development) and interpersonal skills (e.g., team work, communication and project management) were improved/developed. Students needed to hand in their detailed suggestion scheme for the improvement of living environment.

As a researcher and advocate, students can further examine the issues and arrange sharing session, discussion forum, etc. They also took a proactive way to develop and become able to plan, manage and improve their own learning in pursuit of a global issue. The passion and frontline involvement that students gain from the project sharpen their characters as life-long and reflective learners.

The project provided extensive opportunities for students to develop their 'responsible global citizenship'. Through hands-on experience and personal encountering, students developed sense of empathy over the communities living under great impacts of earthquake, hence positively engaged themselves in projects and stimulated interest in subsequent volunteering. While working and living with villagers, appreciation and adaptation to local culture was developed.

\section{B. Service Recipients / Nepalese Community}

Villagers in Katunge (Dhading District, Nepal) was the direct service recipients. The PolyU students worked together with the Kantunge families to enhance their living environment and strengthen their community interactions through the cooperation between PolyU students and the families. The service included:

- Knowledge input through continuous communication and project modifications

- More accurate map for post-disaster redevelopment and land use planning

- Pipe line renewal plan for 20 families

- Have steels for earthquake-proof houses building sorted by students

- Suggestion schemes for environmental and health improvement identified and proposed by the students for FV's implementation

- Raised awareness on personal hygiene and wound management

- Expanded cultural horizon by encountering university students with different background through games

- Received care from students from Hong Kong

- Local empowerment via the villagers' leading role in the service project (i.e., villagers are not helpless "receivers" but they have the ownership to speak and choose)

\section{Hong Kong Community}

Through students' sharing within their own networks (i.e., friends and family), the impact of this project can be amplified to reach the community level:

- Received more information in post-disaster management in Nepal, clarified misunderstanding over education, living standards and danger in disaster-prone areas, especially in rural part of Nepal

- Realised more volunteering opportunities through sharing of information

- Possible enhancement of sense of global citizenship

- Increased awareness on long-term post-disaster relief programme

\section{Feedback from Collaborating NGOs}

"The learning service program was fully consulted with our organisation. Therefore, the outcomes were very positive and really responded to the need of local and our organisation after suffering from massive earthquake in 2015. Firstly, the water facility improvement helped the local families to resolve the problem of insufficient drinking water in the region. Indeed, the stable water supply and safe shelter have been put as the top priorities among earthquake-affected villagers. Secondly, the rebuilt toilet and bathroom helped to 
improve sanitary situation around our education/ community centre. In May 2017, we have reopened Future Village Centre to volunteers and resumed the morning learning classes for village kids. Volunteers and kids are using these new sanitary facilities."

"Thirdly, the mapping trial initiated by the students to draw an accurate map with coordinates and altitudes for the village (in process), if completed, would not only bring new angle to the villagers in understanding their village conditions, and assist the organization in future works planning as well as voluntary visits. Fourthly, the mapping trial was definitely helpful for the professionals to understand the conditions of local environment and the needs of local people. It was shared to Engineers Without Borders (Hong Kong) for developing long-term solutions to relieve the water shortage problem and improve the water supply facilities in the village."

"This was our first experience to host the service learning program to such big student groups. The pre-trip workshops, logistic arrangement, and on-site service allocation were excellent which made the program running smoothly and successfully. We were particularly impressed of students' enthusiasm and opening attitudes towards new environment and culture. All students were self-disciplined, mature, and able to work independently. They demonstrated good understanding and heartfelt care about the needs of the local villagers, which encouraged local villagers to keep positive during post-earthquake-rebuilding."

"For future improvement, we think the program should have 1) longer fieldwork time so that students could have more opportunity to exchange ideas with local villagers, and if possible, work together with locals; 2) more long-run and sustainable elements to be included in the whole programme, such as how the students can apply the new knowledge and skills to help the local community in long-term; 3) follow-up works on mapping, with involvement of the villagers, to create a community map not only functionally present the physical conditions of the village, but also the cultural and heritage features of the village; it may also help the students and volunteers in appreciating the village tradition and culture."

\section{E. Feedback from Student Participants}

Students expressed their satisfaction towards the project in view of the smooth arrangement and meaningful activities. They suggested a longer stay in Nepal to achieve more profound outcomes. Some of their quotes are shown below.

"Keep open this course and let more students join this programme!"

"This trip is meaningful for me, hope that much more students can join this amazing service learning trip. :)"

"The trip is well organized, the schedule is greatly arranged. I particularly like the sharing part of other volunteers, it inspires me a lot."

"Despite the cost, it would be more effective for the learning experience for the productivity of the volunteer group to remain in Nepal a while longer i.e. 2 weeks or best 1 month. However extensive planning of the area, construction and materials, teaching tools, work/aimed projects would be required without it we would be more of a burden to the local rather than the other way around (which unfortunately have occurred from time to time)"

"Less tourism and free time. Should have spent more time in the village. This is a service trip and not a sponsored Nepal sight-seeing trip."

Students also articulated the difficulties encountered and remedial actions taken during the preparatory stage and the service-learning trip.

"Uncertainties in local situation (i.e., changing development plan)"

"Delay in information provision from FV"

"Communication is indirect in Nepal (contacted English speaking founder who spoke to local project manager in Kathmandu, project manager contacted villagers in Katunge Village)"

"Discrepancies in academic ideals and local technology"

"Safety concerns in rural area, health travelling consultation, vaccinations, emergency management (i.e., first-aid kits, first-aiders, emergency services, routes and contacts, back-up in city, etc.) and insurance"

"Project delay in FV affected project tasks set for students: school planned to be built was behind schedule due to changes in labour allocation, a team could not decorate the building walls with local students in programme. Student flexibly adjusted teaching programme to other activities"

"Number of local students attending class varied from day to day (our students managed to change teaching style to accommodate every student who arrived at different times during the day for small classes)"

The outcomes of this project were delivered to other PolyU students, as information collected in this project served as the teaching materials for the four undergraduate courses for different cohorts of students in four engineering programmes. In addition, student participants have been encouraged to join reunion and summer exhibition led by FV, sharing their experience in Nepal with general public and multiply the effect of global citizenship. It will be also a good chance to advertise the need for sustainable and annual projects in different developing areas regarding various aspects including environment, health, education, community development, and so on.

\section{CONCLUSIONS}

This overseas service learning project was organized by the Department of Civil and Environmental Engineering (CEE) of the Hong Kong Polytechnic University (PolyU) and supported by the local non-governmental organization partner, Future Village Nepal (FV). This project aimed to address the post-disaster challenges faced by the victims after the 7.8-magnitude earthquake in Nepal. Forty students were selected and participated in this project to enhance the overall living environment and sustainable community development in Nepal. With the consideration of the local victims' needs, four key themes were formulated in this service learning project, i.e., water supply, wastewater treatment, health and safety education, and GPS mapping. Based on the themes and intended learning outcomes of this project, four pre-trip preparation workshops and a nine-day trip to Nepal were planned to let the participated students being engaged in the 
service with the application of academic knowledge in real-life practice. Reflective journals, questionnaire survey and interviews were adopted to evaluate whether the intended learning outcomes were being met in this project. The intellectual, social, civic, and personal development of students improved as the mean scores of questions in different categories generally increased after the trip. In particular, the students demonstrated an increase of confidence in communication skills and problem solving. Limitations of the programme, such as inadequate local technical support in obtaining data, induced additional learning outcomes as unexpected benefits in students learning. Overall, the intended learning outcomes of this service learning project were met. All four experiential learning processes and six layers of onion model were supported and achieved. This project demonstrated the importance of global citizenship and experiential learning by participating in service learning programme.

\section{ACKNOWLEDGMENT}

The authors appreciate the financial support from the Community Service Fund provided by The Hong Kong Polytechnic University for this study.

\section{REFERENCES}

[1] M. Okamura, N. P. Bhandary, S. Mori, N. Marasini, and H. Hazarika, "Report on a reconnaissance survey of damage in Kathmandu caused by the 2015 Gorkha Nepal earthquake," Soils and Foundations, 2015, vol. 55, pp. 1015-1029.

[2] M. Shakya and C.K. Kawan, "Reconnaissance based damage survey of buildings in Kathmandu valley: An aftermath of $7.8 \mathrm{Mw}$," Engineering Failure Analysis, 2016, vol. 59, pp. 161-18.

[3] G. Chiaro, T. Kiyota, R.M. Pokhrel, K. Goda, T. Katagiri, and K. Sharma, "Reconnaissance report on geotechnical and structural damage caused by the 2015 Gorkha Earthquake, Nepal," Soils and Foundations, 2015, vol. 55, pp. 1030-1043.

[4] D. A. Kolb, Experiential Learning: Experience as the Source of Learning and Development, Englewood Cliffs, NJ: Prentice Hall, 1984.

[5] J. W. Gentry, Chapter 2 - What is Experiential Learning? Guide to Business Gaming and Experiential Learning, Nichols/GP Pub., University of Michigan, 1990, pp. 9-20.

[6] F. Korthagen and A. Vasalos, "Levels in reflection: Core reflection as a means to enhance professional growth," Teachers and Teaching, 2005, vol. 11, pp. 47-71.

[7] F. Korthagen, "In search of the essence of a good teacher: Towards a more holistic approach in teacher education," Teaching and Teacher Education, 2004, vol. 20, pp. 77-97.

[8] A. Y. Kolb and D. A. Kolb, "Learning styles and learning spaces: Enhancing experiential learning in higher education," Academy of Management Learning \& Education, 2005, vol. 4, pp. 193-212.
[9] F. Korthagen and F. G. Evelein, "Relations between student teachers' basic needs fulfillment and their teaching behaviour," Teaching and Teacher Education, 2016, vol. 60, pp. 234-244.

Daniel C. W. Tsang is currently an associate professor in the Department of Civil and Environmental Engineering at the Hong Kong Polytechnic University. He was an IMETE visiting scholar at Ghent University in Belgium, visiting scholar at Stanford University in the US, senior lecturer and lecturer at the University of Canterbury in New Zealand, and post-doctoral fellow at Imperial College London in the UK and the Hong Kong University of Science and Technology. With a strong link to real-world environmental challenges, Dan's research group strives to develop cost-effective and low-impact solutions to ensure sustainable urban development, enhance the engineering infrastructure, and create new ways in which we manage contaminated soils/sediments, municipal solid waste, and urban waters. Dan has published over 170 SCI journal papers and received Excellence in Review Award for Environmental Science and Technology and Chemosphere. He has served as Guest Editor for Bioresource Technology, Chemosphere, Science of the Total Environment, Journal of Cleaner Production, Journal of Hazardous Materials, etc. He currently serves as Editorial Board Member of Chemosphere, Associate Editor of Journal of Soils and Sediments and Environmental Geochemistry and Health. Dan is chair and organizer of 2nd Biological Waste as Resource Conference (BWR2017, Hong Kong) and 4th Contaminated Land, Ecological Assessment and Remediation Conference (CLEAR2018, Hong Kong).

Lu B. L. Khoo received her bachelor's degree in environment and sustainable development from the Hong Kong Polytechnic University. As a project assistant in the Civil and Environmental Department, she took lead in organizing teaching projects on engineering teaching programmes and service learning programme on environmental improvement in Nepal; as well as assisted research projects on treatment of fracturing wastewater and biorefinery of food waste into value-added chemicals. She is currently studying oceanography in University of Southampton.

Iris K. M. Yu is currently a $\mathrm{PhD}$ candidate in the Department of Civil and Environmental Engineering at the Hong Kong Polytechnic University. Her research interest lies in sustainable waste management as an important element in the global environmental agenda. She has published 22 SCI journal papers since 2016 and received Outstanding Contribution in Review Award for Journal of Cleaner Production.

Nicole S. N. Yiu is a teaching fellow in the Department of Civil and Environmental Engineering at the Hong Kong Polytechnic University. She is the deputy programme leader of $\mathrm{BSc}$ (Hons) in environmental and occupational safety $\&$ health. She teaches various occupational safety and health subjects and service learning subject. She involves in organizing student outreach events and supervising students' academic and community service projects. For the engaged service projects, she acts as a supervisor to ensure students working effectively in a team to solve problems and apply their professional knowledge to serve the community and as a coordinator to ensure effective communication with clients and stakeholders. Before joining The Hong Kong Polytechnic University, she also worked as a safety practitioner in local construction industry for 8 years. She is qualified, by profession as per legal requirements, to conduct safety and health training accordingly to the training needs of the participants; devise safety rules, emergency procedures and safety plan; conduct safety and health accident or incident investigation so as to prevent its similar re-occurrence. 